\title{
The Value of Yoga Practice in Managing the Risk Factor of Stress in Heart Disease
}

\author{
Maricarmen Cruz Jimenez* \\ Department of Physical Medicine and Rehabilitation, Puerto Rico
}

Submission: November 15, 2017; Published: November 27, 2017

*Corresponding author: Maricarmen Cruz Jimenez, Department of Physical Medicine and Rehabilitation, Casia \#10, San Juan, PR 00921, Puerto Rico, Tel: 787-641-7582x32900; Email: Maricarmen.Cruz-Jimenez@va.gov

\section{Introduction}

Cardiovascular disease is a leading cause of mortality for men and women in the world [1]. The associated risk factors are well described and are essentially related to lifestyles; when modified, they have an important impact on primary and secondary prevention. Among these risk factors are: abnormal cholesterol, elevated blood pressure, diabetes mellitus, abdominal obesity, smoking, unhealthy diet, lack of physical activity, excessive alcohol intake, and psychosocial stress [2]. As the number of risk factors increase for an individual, so does the risk of suffering a cardiovascular event, so identifying and managing these risk factors will consequently influence cardiovascular disease and its outcomes.

There are concrete recommendations on how patients should approach disease modification for every modifiable risk factor described for cardiovascular disease. Secondary prevention centers on educating patients on their individual risk factors, and on how to modify them based on their preferences and resources. Many of these recommendations include evidence based guidelines that lead providers into algorithms that allow moving into other treatment options when the intended management fails or does not provide the expected outcomes. In stress management, these guidelines are less systematic, and evidence based alternatives in heart disease are limited. Providers could be confronted with the ambitious challenge of trying to identify the varied number of life stressors affecting the patient's life, while seeking realistic alternatives to present specific recommendations to manage these stressors [3].

\section{Stress and disease}

Stress may be defined as any external event or condition that affect the organism [4]. Stressors may include minor and major life events, such as changes in patient's life role, loss of financial or personal resources, loss of a spouse, and health conditions, among some. Individuals may experience different ways of perceiving and coping with stress; they may choose to confront the problem that is causing stress, confront the emotion associated to stress, or both [5]. In this conscious appraisal of recognizing that stress is present is when the patient may choose to share that information with the provider, who consequently can assess, coach, treat and/or refer. If stress is not recognized and confronted, there is physical and psychological adaptations to stress that will lead to changes in behaviors and physiology.

Sustained stress may contribute to worsen behaviors that already predispose the patient to existing heart disease, like hypertension, obesity, alcohol drinking, smoking and physical inactivity [6]. Stress may cause disease too by increasing the resting metabolic rate on the balanced physiology, and there are several pathophysiologic pathways in which this may happen. Stress has been related to an imbalance in the autonomic nervous system (ANS). In stress, the sympathetic nervous system increases the release of noradrenaline from the brain and adrenaline from the adrenal medulla, leading to an increment in heart rate, and blood pressure. Sympathetic dominance may influence the complete cardiac cycle or heart rate variability [7]. Sustained stress may lead too to increments in cortisol levels. This occurs through the activation of the hypothalamic-pituitary axis which activates substances like corticotrophin releasing hormone ( $\mathrm{CRH})$, and adrenocorticotrophic hormone (ACTH). This chain of events lead to increased levels of corticosteroids, and eventually cortisol [8]. Consequent sustained inflammatory responses end up being associated to atherosclerotic heart disease [9]. Other factors like circulating interleukin-6 (IL-6) may in addition stimulate the hypothalamic -pituitary -adrenal (HPA) axis, increasing cortisol release, and eventually leading to obesity, insulin resistance and hypertension [10]. 


\section{Managing stress}

Stress is a known risk factor that requires management in heart disease, and even though there are multiple strategies that could be used, concrete guidelines on how to follow a step by step recommendation may be limited. Handling the conversation of lifestyles modification requires time to build up trust and allow the patient confront the reality of this risk factor impact in health outcomes. In stress management, patients are generally recommended to improve their sleep hygiene, exercise routines, use time management techniques, use of diaries to keep track of events and emotions, participate from cognitive behavior therapy and relaxation techniques [11]. Awareness on the scientifically supported strategies can assist the provider on presenting sound recommendations.

There are therapeutic options with good scientific evidence that are used to manage stress in heart disease. Cognitive behavioral intervention teaches the patient to examine and recognize emotions and thoughts that lead to stress, and teaches them strategies that change their thinking and consequent behavior [12]. In cardiovascular disease, cognitive behavior therapy has been more consistently used for the management of stress and proven to influence a reduction in the fatal and non-fatal recurrence of events [13]. Meditation is another intervention that is considered by the American Heart Association as an adjunct therapy due to the possible benefits of reducing cardiovascular risk to a low cost and to a low risk, particularly if the patient is interested in lifestyle changes [14]. Yoga is another therapeutic option that not only has demonstrated to improve stress, but it effects over objective parameters that lead to physiologic stress and chronic disease.

\section{The role of yoga in heart health}

Yoga is considered a complementary health approach used by millions of adults in the United States that seeks incorporating mind, body and spirit into routines of physical movements that result in mental relaxation. Even though there are different yoga schools that are distinguished by different practice styles, they all incorporate core practices that include: breathing, postures and meditation. Postures lead to improved flexibility and strength; and controlled breathing helps focusing the mind into a relaxed state, which permits meditation. Even when the number and quality of randomized controlled trials in yoga in heart disease may be considered limited, there is a significant number of studies that are emerging supporting the role of yoga in cardiovascular health. The evidence is stronger suggesting that there is a role of this practice in influencing the outcomes in primary prevention. Patients with high risk for heart disease experience improvements in diastolic blood pressure, triglycerides, and high density lipoprotein levels [15]. In secondary prevention, the effectiveness of yoga on the physical fitness parameters as required in heart disease remains questionable [16]. But in stress management, the impact of yoga in heart disease is different [17].

Yoga practice leads to regulation of the sympathetic nervous system and the hypothalamic-pituitary-adrenal axis, which consequently lead to changes in the neurohormonal environment. The breathing technique allows relaxation of the body and the limbic system, permitting a balanced between the sympathetic and parasympathetic systems. The eventual result is a slowing of the heart rate and a decrement of the blood pressure $[18,19]$. The regular long term practice of yoga may lead to reduced heart, breath, and metabolic rate, heart rate variability and improved lung function; and depending on the duration of practice, improvements in heart rate, blood pressure and respiratory rate [20].

\section{Just “breath"}

Breathing is an essential component to relaxation and consequent stress release; relaxation leads to a meditative state, that permits deeper relaxation and the consequent physiologic changes. This relaxation produced by the combination of breathing and meditation induces a hypometabolic state that is associated to psychophysiological activity and reduction in oxygen consumption as high as $40 \%$. This so called "yogi state" in which there is a mind-body connection, may be voluntarily induced through learned yoga breathings. Breathing is consciously observed with the intention of turning the attention to oneself and keeping away the external thoughts; breathing helps focusing the mind on the present state, and not on wondering from worries to obligations. Once the mind is quiet, meditation comes in permitting observation of objects and/or thoughts without the emotional reaction or judgement. It is this meditative observation that allows the patient to study the individual behaviors and reactions that, in front of certain situations, may lead to emotional responses, like sadness, anger, and stress, among some. Meditation allows the patient to learn a different response to a stressful situation. Breathing patterns include deep breathing into the abdomen, breathing against airway resistance, physical postures, holding the breath at different parts of the breath cycle, breathing alternating air through the both nostrils, or only one nostril.

The importance of breathing is that there is a reciprocal relation between breathing and emotions, meaning that emotional states influence the respiratory pattern, while changes in the respiratory patterns influence the emotional state. Improvements in breathing pattern have been associated to variance in the feeling of anger, fear, joy and sadness [21]. 


\section{Summary}

At any age, yoga practice can provide health benefits incorporating physical activity, breathing and meditation. Yoga has demonstrated benefits in heart disease, not only by managing breathing and stress, but by influencing the body physiology associated to having a balanced body and mind. Regular training may positively influence the patient into incorporating healthier lifestyles that, in combination with the modification of other risk factors, may enhance secondary prevention interventions. The benefits of yoga are not limited to healthier lifestyles. Regular yoga practice has proven its physiologic benefits over the stress physiology and the consequent disease state, eventually influencing parameters that directly ameliorate stress generators.

Finally, yoga principles teach patients to connect to themselves through meditation, and to connect to the inner self in an accepting way. There could be multiple external reasons for suffering stress, but only one internal soul experiencing it. Even when there are other options to stress management, the principles of meditation in yoga practice will help patients expand their understanding of themselves, reflect from their reactions to stress with self-compassion, and accept their circumstances with eventual calmness.

\section{References}

1. https://www.cdc.gov/heartdisease/facts.htm

2. Benjamin EJ, Blaha MJ, Chiuve SE, Cushman M, Das SR, et al. (2017) Heart Disease and stroke statistics - 2017 update: a report from the American Heart Association. Circulation 135: e146-e603.

3. Blumenthal JA, Sherwood A, Smith PJ, Watkins L, Mabe S, et al. (2016) Enhancing cardiac rehabilitation with stress management training. A randomized, clinical trial. Circulation 133(14): 1341-1350.

4. Breznitz S, Goldberger L (1993) Stress research at a crossroads. In: Goldberger L, Breznitz S (Eds.), Handbook of stress: theoretical and clinical aspects. ( $2^{\text {nd }}$ edn), Free press, New York, USA, p. 819.

5. Segerstrom SC, O'Connor DB (2012) Stress, health and illness: four challenges for the future. Psychol Health 27(2): 128-140.

6. Stress and heart health.
7. Maheswari M, Ann GT (2017) Effect of Yoga on the autonomic nervous system: clinical implications in the management of atrial fibrillation. J Yoga \& Physio 3(1): 555601.

8. Casey G (2017) Stress and disease. Kai Tiaki Nursing New Zealand 23(6).

9. Troxler RG, Sprague EA, Albanese RA, Fuchs R, Thompson AJ (1977) The association of elevated plasma cortisol and early atherosclerosis as demonstrated by coronary angiography. Atherosclerosis 26(2): 151-162.

10. Yudkin JS, Kumari M, Humphries SE, Ali VM (2000) Inflammation, obesity, stress and coronary heart disease: is interleukin- 6 the link? Atherosclerosis 148(2): 209-214.

11. (2017) Stress and heart health. American Heart Association.

12. Grazebrook K, Garland A (2005) What are cognitive and/or behavioral psychotherapies? International Institute for Cognitive therapy.

13. Gulliksson M, Burell G, Vessby B, Lundin L, Toss H, et al. (2011) Randomized controlled trial of cognitive behavioral therapy vs. standard treatment to prevent recurrent cardiovascular events in patients with coronary heart disease. Secondary prevention in Uppsala Primary Healthcare Project (SUPRIM). Arch Intern Med 171(2): 134140.

14. Levine GL, Lange RA, Bairey Merz N, Davidson RJ, Jamerson K, et al (2017) Meditation and cardiovascular risk reduction: a scientific statement from the American Heart Association. JAMA 6(10).

15. Hartley L, Dyakova M, Holmes J, Clarke A, Lee MS, et al. (2014) Yoga for the primary prevention of cardiovascular disease. Cochrane Database Syst Rev (5): CD010072.

16. Kwong JSW, Lau HLC, Yeung F, Chau PH (2015) Yoga for the secondary prevention of coronary heart disease. Cochrane Database of Systematic Reviews.

17. Kuehn BM (2017) Emerging data support benefits of yoga for patients with heart disease. Circulation 135: 398-399.

18. Mehta JL, Mehta P, Pai BV (2017) Yoga and cardiovascular disease. J of Yoga and Physiotherapy 3(1): 555604.

19. Hart J (2016) The effects of yoga on physiologic stress parameters. Alternative and Complementary Therapies 22(2): 72-73.

20. Tyagi A, Cohen M, Reece J, Telles S (2014) An explorative study of metabolic responses to mental stress and yoga practices in yoga practitioners, non-yoga practitioners and individuals with metabolic syndrome. BMC Complement Altern Med 14: 445.

21. Brown RP, Gerbard PL (2009) Yoga breathing, meditation, and longevity. Ann NY Acad Sci 1172: 54-62.

\section{Your next submission with Juniper Publishers} will reach you the below assets

- Quality Editorial service

- Swift Peer Review

- Reprints availability

- E-prints Service

- Manuscript Podcast for convenient understanding

- Global attainment for your research

- Manuscript accessibility in different formats

( Pdf, E-pub, Full Text, Audio)

- Unceasing customer service

Track the below URL for one-step submission https://juniperpublishers.com/online-submission.php 